\title{
-

\section{A educação de adultos na sociedade contemporânea: perfil de competências do educador}

\author{
Adult education in contemporary society: profile of the educator's \\ competences
}

\author{
Albertina Lima de Oliveira \\ Universidade de Coimbra \\ Marco Antônio Franco do Amaral \\ Instituto Federal Goiano
}

Recebido em 18 de agosto de 2018

Aprovado em 30 de abril de 2019

Publicado em 18 de junho de 2019

\section{RESUMO}

Os múltiplos desafios educativos e formativos de públicos adultos nas sociedades contemporâneas têm conduzido à necessidade, nos planos nacional e internacional, de mais reflexão e investigação em torno dos saberes e competências fundamentais dos profissionais da educação de adultos, de modo a potenciar uma atuação responsável e a prestação de serviços de qualidade. Neste âmbito, ouvir a voz dos que mais têm se dedicado à reflexão teórica e política, bem como a dos agentes que no terreno têm construído saber de experiência feito, reveste-se de grande importância. Este estudo pretende identificar as competências-chave do educador de adultos na sociedade contemporânea e contribuir para enriquecer o debate nacional internacional sobre o tema. De modo a cruzar pluralidades de olhares, levamos a efeito um estudo Delphi que integrou um painel de 14 especialistas do meio acadêmico e agentes do terreno com experiência substancial de trabalho com públicos adultos. Após a realização de 4 voltas foi possível chegar a um consenso significativo. A análise das competências propostas conduziu aos 7 seguintes clusters: ética; mobilização e valorização da experiência de vida; facilitação da aprendizagem; métodos e técnicas de educação, formação e aprendizagem; planejamento, gestão e avaliação do processo formativo; autodesenvolvimento; e ligação à comunidade. $\mathrm{O}$ conjunto das competências reportadas inscrevem-se maioritariamente em posicionamentos teóricos humanistas, reflexivos e críticos.

Palavras-chave: educação de adultos; competências do educador de adultos; estudo delphi. 


\section{Autuaŗão}

ISSN: 1984-6444 | http://dx.doi.org/10.5902/1984644434349

\section{ABSTRACT}

The multiple challenges in educating and training adult audiences in contemporary societies have led to the need for more reflection and research on the core competences of adult education professionals, both at national and international levels, in order to provide services with high quality. In this context, listening to the voice of those who have devoted themselves to theoretical and political reflection, as well as to the agents who have built up knowledge based on experience, is of great importance. This study intends to identify the key competences of the adult educator in contemporary society and to contribute to enrich the national and international debate on this theme. In order to cross-check multiple perspectives, we conducted a Delphi study that included a panel of 14 academic experts and field agents with substantial experience working with adult audiences. After 4 rounds, it was possible to reach a significant consensus. The analysis of the proposed competences led to the following 7 clusters: ethics; mobilization and recognition of prior learning; learning facilitation; methods of education, training and learning; planning, management and evaluation of the training process; self-development; and connection to the community. The set of competencies reported are mostly based on humanistic, reflexive and critical theoretical frameworks.

Keywords: adult education; key-competences of adult educators; delphi study.

\section{Introdução}

Construir sociedades em que os cidadãos participem de um processo contínuo de formação, ao longo e em todos os espaços da vida, continua a ser um dos mais pertinentes desafios educativos do nosso tempo. Para esta concretização os educadores de adultos são de indiscutível necessidade, porém, nunca se alcançaram os objetivos ambicionados, nem em Portugal nem na esfera internacional.

A educação de todas as pessoas, particularmente das adultas, sob uma matriz formativa e emancipatória consistente, embora inscrita na ambição renovadora e revolucionária da Educação Permanente (DAVE, 1979; SIMÕES, 1979), nunca se tornou um objetivo político efetivo, nem se criaram condições que a pudessem concretizar. As medidas políticas enfermam em geral da miopia do curto prazo e do desejo de resultados rápidos, e, na era do descartável e efémero, quando se começam a criar condições para programas de ação viáveis, amplos e sustentadores de transformações positivas, como aconteceu em Portugal em finais do século XX com a 


\section{Authabูão}

ISSN: 1984-6444 | http://dx.doi.org/10.5902/1984644434349

criação da Agência Nacional para a Educação e Formação de Adultos (ANEFA), estes desmoronam-se como sucedeu, por exemplo, com as equipas dos Centros Novas Oportunidades (CNO) em 2011 - "um desperdício do conhecimento que foi sendo construído, bem como dos recursos materiais e financeiros colocados ao serviço da EFA" (PORTUGAL, 2013).

As fortes raízes humanistas presentes no conceito de educação permanente deram lugar ao predomínio da matriz de pensamento neoliberal, subjacente ao conceito de aprendizagem ao longo da vida, a partir de meados da década de 90 do século passado, nas políticas, discursos e práticas da educação em geral e, particularmente, da educação de adultos (LIMA, 2016). Horizontes inclusivos, respeitadores dos equilíbrios dos ecossistemas e integradores da vida em toda a sua diversidade, são ainda uma miragem. A insegurança e incerteza, a violência, a precariedade no trabalho, a competitividade feroz, a procura desmedida do lucro, a exploração das pessoas e a ação destrutiva sobre os recursos naturais e ecossistemas constituem problemas graves do nosso mundo, revelando a incapacidade de se instituírem sociedades regidas pelos mais elevados valores (IRELAND; SPEZIA, 2014).

Mais do que nunca precisamos reposicionar e fortalecer a educação de adultos no seu caminho de compromisso com a formação de cidadãos esclarecidos e críticos, apoiando a emergência do melhor da sua humanidade e tornando-os capazes de contribuir decisivamente para mudar de rumo face as forças dominantes nas sociedades contemporâneas (MELO, 1996) e de formar educadores de adultos comprometidos com a educação transformadora das pessoas e dos seus contextos de pertencimento (MELO, 2001; BRANDÃO, 2009; FRAGOSO; KURANTOWICZ; LUCIO-VILLEGAS, 2011).

Desde a CONFINTEA de Paris a UNESCO chama a atenção para a necessidade de formação de profissionais de Educação de Adultos (EA) que tenham uma noção clara do seu papel e que sejam competentes no seu modo de estar, agir e ser. Muito embora a investigação seja dificultada pelo fato da profissionalização do domínio ser uma raridade e de não existir uma identidade clara destes profissionais, por diversas razões há uma estreira ralação entre as políticas públicas e a construção 


\section{Autuaŗão}

ISSN: 1984-6444 | http://dx.doi.org/10.5902/1984644434349

do campo em cada país (JARVIS, 2004) - mas também porque os educadores de adultos operam em domínios, instituições e contextos bastante diversos (com infraestruturas, lógicas, propósitos, tarefas, e participantes muito diferentes), sendo o caso das instituições educativas formais (cursos EFA - Educação e Formação de Adultos) e não formais (universidades seniores), da formação profissional e contínua, da educação comunitária, das atividades nas esferas sociocultural e recreativa, entre outras - constata-se um trabalho de investigação já assinalável.

A pesquisa internacional (SOARES, 2011; LOUREIRO, 2009; ROTHES, 2003) aponta para um conjunto de competências essenciais, as quais reúnem um razoável consenso entre vários países e culturas, apesar da complexidade e diversidade de papéis desempenhados e das especificidades das esferas ocupacionais em que os educadores de adultos intervêm. Ao rever alguns dos mais importantes estudos no domínio, Wahlgre (2016) salienta alguma variabilidade no perfil de competências do educador de adultos, quer em termos de número quer de importância das mesmas ${ }^{1}$, mas também afirma ser fácil encontrar semelhanças, sendo recorrente a emergência de categorias como competências de comunicação, de análise de necessidades, de reconhecimento das experiências das pessoas adultas, bem como competências de gestão de grupos.

Reportando-se ao estudo de Surikova et al. (2015), que comparou países oriundos de matrizes culturais muito diversas, tais como Índia, Letónia e Lituânia, apesar das diferenças terem emergido, Wahlgre (2016) refere ter-se constatado que os 3 países "colocam no topo das prioridades o desenvolvimento da competência de manter um estado de equilíbrio emocional, de abertura e de atenção" (2016, p.350). Em busca de competências comuns, transversais aos contextos onde o educador desenvolve a sua atividade, o autor conclui o seu trabalho de revisão sistematizando quatro categorias temáticas: 1) comunicar o assunto de forma compreensiva e inspiradora, recorrendo a métodos pedagógicos apropriados; 2) relacionar-se com as condições em que os educandos se encontram, em sentido lato; 3) criar ambientes de

\footnotetext{
${ }^{1} \mathrm{O}$ autor na sua análise considerou estudos Delphi e estudos sobre perfis de países europeus com sistemas mais definidos (Alemanha, França, Suiça e Reino Unido). Integrou ainda o contexto da formação profissional (CEDEFOP, 2013).
} 


\section{Autuaŗão}

ISSN: 1984-6444 | http://dx.doi.org/10.5902/1984644434349

aprendizagem construtivos, pautados pelo compromisso, confiança e tolerância, bem como por relações positivas entre educandos e educador-educandos; 4) refletir sobre a própria experiência de forma a melhorar constantemente os seus desempenhos. Para além destas, o autor considera importante incluir também a habilidade para preparar a transferência das aprendizagens. Sem deixar de ser importante esta proposta, ela tende a inscrever-se num contexto de cariz mais formal em que a aprendizagem ocorre em espaços e tempos segregados das dinâmicas da vida cotidiana e dos contextos social e cultural das pessoas, decorrendo daqui, em nosso entender, a ênfase e o apelo à importância da transferência das aprendizagens.

Para, além disso, o apecto revolucionário, renovador e transformador da educação de adultos, vertido nos princípios subjacentes à estruturação deste campo pela UNESCO $(1976)^{2}$, de fundo humanista e emancipatório, remete-nos incontornavelmente para a consideração das características pessoais e contextos de vida (cultural, social, ocupacional, familiar etc.) dos educandos, trazendo a vida para o currículo e o currículo para a vida (QUINTAS, 2008).

Numa outra latitude, que se prende com a realidade brasileira, e debruçandose também sobre a problemática da formação do educador de adultos, Soares (2011), ao analisar três projetos e um centro de Educação de Jovens e Adultos (selecionados tendo por base critérios como o tempo de existência, o histórico, a tradição, o impacto na área e a relevância para a comunidade envolvida), chega a inferir oito aspectos que lhe conferem especificidade ${ }^{3}$, e que mobilizam princípios orientadores de práticas educativas teoricamente situadas na abordagem Freiriana. Em nível do oitavo aspecto, ligado aos desafios de formulação de políticas públicas, é contestada a falta de profissionalização dos educadores de EJA, que os mantém 'reféns' do amadorismo e improviso, com repercussões na qualidade do trabalho desenvolvido. Efetivamente, tal como na Europa, a necessidade de formação específica para se trabalhar na

\footnotetext{
2 Princípio j) da recomendação de Náirobi.

3 1) o modo como surge cada projeto; 2) a diversidade de sujeitos; 3) o espaço físico; 4) formas de conceber as propostas curriculares e de as associar à realidade dos sujeitos concretos; 5) disponibilidade de recursos didáticos que atendam e desenvolvam as potencialidades dos adultos; 6 ) políticas compensatórias de alimentação e transporte; 7) política pública que efetive sua oferta com qualidade 8) iniciativas de formação inicial e continuada de educadores.
} 


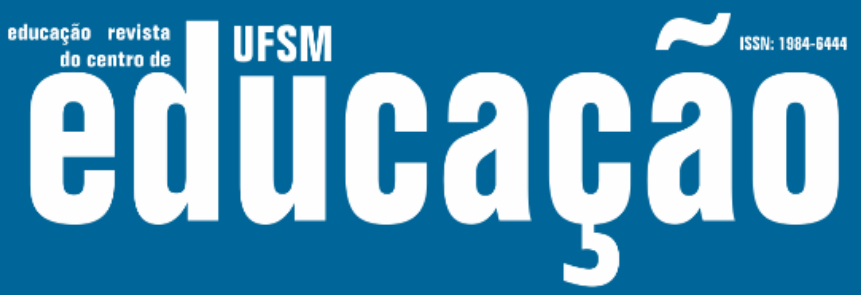

ISSN: 1984-6444 | http://dx.doi.org/10.5902/1984644434349

Educação de Adultos é salientada, "desde reconhecer a realidade dos sujeitos da EJA, passando pela formulação de propostas curriculares coadunadas a essas realidades, indo até a criação de recursos didáticos que enriqueçam e estimulem a aprendizagem dos jovens e adultos" (SOARES, 2011, p. 316). Comum às quatro experiências educativas realizadas, como destaca o autor, é a relação entre teoria e prática na formação do educador, ou seja, é preciso que nas atividades pedagógicas se dedique tempo a estudos e reflexões permanentes sobre a prática.

Em Portugal, desde a instituição da Lei de Bases do Sistema Educativo (1986), a Educação de Adultos foi marcada por uma acentuada crise e desinstitucionalização, da qual só se iniciaria a recuperação em finais da década de 90 , do século XX, com o Programa de Ação S@ber+: Programa para o Desenvolvimento e Expansão da Educação e Formação de Adultos (1999-2006), cuja execução ficou a cargo da ANEFA (Agência Nacional para a Educação e Formação de Adultos). Implicando uma reorganização de fundo, o campo ressurge inscrito num quadro filosófico de aspecto humanista e, por isso, assente nos melhores princípios da educação de adultos, passando a existir um sistema de educação e formação de adultos integrado com uma oferta de percursos formativos diversificados, dentre os quais, e pela primeira vez, o reconhecimento e validação de saberes e competências adquiridas em contextos informais e não formais.

Em termos legislativos, criaram-se condições para uma maior diversificação de importantes papéis profissionais do educador de adultos como, por exemplo, o de Profissional de Reconhecimento e Validação de Competências (RVC). Com a criação de 459 CNO (Centros Novas Oportunidades), até à sua extinção em 2011 (Conselho Nacional de Educação, 2013), havíamos atravessado um período de grande fulgor no campo da Educação e Formação de Adultos e, simultaneamente, impunha-se a necessidade de reflexão crítica sobre todo o sistema e o papel dos educadores de adultos, atendendo à inflexão da política educativa que progressivamente passou a subordinar-se às orientações supranacionais de europeização, a inscrever-se na ideologia neoliberal (Barros, 2016) e a exercer fortes pressões sobre as equipes dos Centros Novas Oportunidades para alcançar as metas de certificação comprometendo a sua ação formativa e emancipatória. 


\section{Autuaŗão}

ISSN: 1984-6444 | http://dx.doi.org/10.5902/1984644434349

Numa análise das "ocupações da educação de adultos", a partir de documentos que abrangeram o período entre 2001 e 2016, Guimarães (2016, p. 74) constata que em nenhum dos diplomas legais consultados, nem tão pouco em discursos políticos ou outros documentos oficiais encontrados, foi possível identificar a expressão "educador de adultos". Neste âmbito, e após uma revisão e reflexão de grande pertinência sobre o tema, a autora sistematiza cinco desafios: 1) a ampla diversidade e complexidade do campo da Educação de Adultos; 2) o caráter intermitente e descontínuo das políticas públicas; 3) a inexistência de formação inicial específica de educadores de adultos nos estabelecimentos de ensino superior; 4) a saliência da componente relacional, sobretudo nas atividades dos profissionais de RVC, comparativamente a atividades mais tradicionais do campo da educação de adultos; e 5) riscos dos profissionais de RVC estarem reféns da "instrumentalidade da racionalidade técnica". Sublinha, ainda, a necessidade de se favorecerem os processos de reflexão crítica e política "acerca do trabalho realizado e dos sentidos desse trabalho atribuídos pelos próprios educadores permitindo à educação de adultos reconquistar a sua dimensão educativa" (GUIMARÃES, 2016, p. 75).

Perante estes desafios, e ainda no rescaldo da grande movimentação educativa e formativa que ocorreu em Portugal em termos de educação de adultos neste nosso século ${ }^{4}$, reveste-se de grande importância ouvir a voz dos que mais se dedicaram à reflexão teórica e política, bem como a dos agentes que no terreno construíram saber de experiência feito, sobre os papéis e competências dos educadores de adultos. Neste artigo apresentamos os resultados de um estudo realizado com um painel de especialistas portugueses com trabalho reconhecido no domínio, através do método Delphi, em que se pretendeu clarificar e alcançar um consenso alargado acerca do que consideram ser as competências-chave dos educadores de adultos.

\footnotetext{
${ }^{4}$ De referir que o número mínimo de 3 anos se deve ao facto de termos incorporado no painel um membro que desempenhava a atividade de Técnica de Reconhecimento e Validação de Competências, considerada com grande competência no domínio e, por essa razão, ter ministrado formação aos técnicos que pertenciam às equipes dos Centros Novas Oportunidades na Região Centro, através da Universidade de Coimbra.
} 


\section{ح

ISSN: 1984-6444 | http://dx.doi.org/10.5902/1984644434349

\section{Metodologia}

A opção metodológica pela técnica Delphi deveu-se ao fato de ser especialmente indicada para alcançar consensos válidos sobre assuntos em relação aos quais não há respostas certas, a partir de um grupo reduzido de pessoas reconhecidas como especialistas. A natureza desta técnica permite que os resultados reflitam o que as pessoas verdadeiramente pensam, porque não estão sujeitas a influências persuasivas dos membros do grupo e têm informação sobre a posição dos demais, relativamente a cada ideia proposta através de retorno sistemático, o qual permite que cada participante perceba até que ponto a sua posição se aproxima ou distancia da do grupo. Gera-se, assim, a oportunidade de cada membro repensar a sua opinião comparativamente às dos elementos do grupo, à medida que o processo de aplicação da técnica evolui. Com este método conjuga-se o pensamento independente e a reflexão suscitada pelos aportes dos membros do grupo, o que poderá levar a mudanças de opinião mais refletidas (Amado, 2017).

\section{Participantes}

Participaram no painel 14 especialistas portugueses com perfis heterogêneos ${ }^{5}$ com a intenção de refletir a diversidade do campo da educação de adultos: académicos; especialistas em políticas públicas; especialistas em planeamento e gestão de programas de educação/formação de adultos; formadores; e profissionais de reconhecimento e validação de competências. Os anos de experiência profissional em EA dos elementos do painel situaram-se entre 3 e 40 anos $^{6}$, com uma média de

\footnotetext{
${ }^{5}$ Alberto Melo, Rui Canário, António Simões, Belmiro Cabrita, Paula Guimarães, Inácio Nogueira, Mário Caramujo, Sandra Saúde, Luísa Pinhal, Tânia Marques, Tomás Neves, Maria do Carmo, Carla Franco e Pedro Silva. Reiteramos os nossos agradecimentos a todos estes especialistas de EA pela gentil e prestimosa colaboração nesta investigação.

${ }^{6}$ De referir que o número mínimo de 3 anos se deve ao facto de termos incorporado no painel um membro que desempenhava a atividade de Técnica de Reconhecimento e Validação de Competências, considerada com grande competência no domínio e, por essa razão, ter ministrado formação aos técnicos que pertenciam às equipes dos Centros Novas Oportunidades na Região Centro, através da Universidade de Coimbra.
} 


\section{Autuaŗão}

ISSN: 1984-6444 | http://dx.doi.org/10.5902/1984644434349

20.39. Relativamente à sua formação de base, esta revelou ser heterogênea, variando entre Relações Internacionais, Ciências da Educação, Gestão de Recursos Humanos, Direito, Psicologia, História, Economia, Filosofia, Sociologia, Magistério Primário, e Ciências Físico-Químicas. Quanto ao grau académico, 3 eram licenciados, 7 mestres, 1 pós-graduado e 3 doutorados.

\section{Procedimento}

Para além da constituição do painel de especialistas, a implementação da discussão Delphi requer que se elabore um questionário resultante dos contributos do grupo e que este seja enviado a todos os participantes na discussão para classificação dos seus itens e introdução de novos itens ou exclusão de alguns, de acordo com as opiniões manifestadas nas diversas voltas. Ao longo do processo de reflexão, os questionários foram revistos e refeitos várias vezes até ser alcançada uma convergência substancial de opiniões. Assim, após a explicação dos objetivos do estudo e o tipo de participação desejada bem como a obtenção de consentimento, o processo iniciou-se com a seguinte questão aberta, enviada por correio eletrônico a todos os membros do painel: Do seu ponto de vista, quais são as competências-chave, conhecimentos e atitudes que um educador de adultos precisa mobilizar para desempenhar, com qualidade, os seus diferentes papéis, funções e tarefas??

Partindo desta questão, foi solicitado a cada membro do painel que redigisse uma lista de competências, de forma totalmente livre, com base na sua experiência, conhecimentos e reflexões. A partir das respostas recebidas, elaborou-se uma lista resultante da integração de todas as ideias geradas pelo grupo, a qual deu origem a um questionário inicial com 70 itens. Este questionário foi, seguidamente, reencaminhado a todos os participantes, tendo em vista a classificação de cada item numa escala de importância de 0 (nada importante) a 7 (extremamente importante).

\footnotetext{
${ }^{7}$ No presente artigo, dadas as limitações de espaço, só nos é possível abordar a parte da questão relativa às competências-chave dos educadores de adultos.
} 


\section{N-Tism \\ Eutlatgat}

ISSN: 1984-6444 | http://dx.doi.org/10.5902/1984644434349

Compiladas as respostas ao questionário da $1 .^{\text {a }}$ volta, calcularam-se para cada item os valores do primeiro quartil $\left(Q_{1}\right)$, da mediana $\left(Q_{2}\right)$ e do terceiro quartil $\left(Q_{3}\right)$, e reenviou-se um segundo questionário a todos os participantes, com indicação das estatísticas mencionadas, a sinalização dos itens em que menos de $25 \%$ de colegas haviam pontuado de forma idêntica e com a adição de 4 novos itens, propostos nas respostas ao questionário da 1. a volta. Neste segundo questionário pedia-se aos membros do painel que reconsiderassem as suas respostas mais divergentes, no sentido de as aproximar das do grupo maioritário, ou, então, que justificassem as suas opiniões, caso decidissem manter as pontuações atribuídas previamente (2.․ volta).

Da 2. ${ }^{\text {a }}$ para a 3. ${ }^{\text {a }}$ volta verificaram-se mudanças substanciais rumo ao consenso, uma vez que $71.5 \%$ de pontuações convergiram para os valores da maioria. Por outro lado, a partir dos comentários que se foram gerando ${ }^{8}$, procedeu-se a eliminação e agregação de itens, totalizando no final 53 (3. ․ volta). Nesta última volta a amplitude real das pontuações (que poderia variar entre 0-98, em função da escala de resposta) situou-se entre 52 e 89 - acima do ponto médio da escala de resposta aos itens (situado em 49), o que significa que todos os itens foram pontuados acima de moderadamente importantes, pelo que considerámos estarem reunidos elevados consensos entre os membros do painel, razão pela qual finalizámos a discussão (4. ${ }^{\text {a }}$ volta).

\section{Resultados}

O quadro 1 apresenta as competências consideradas no topo da hierarquia de importância pelos membros do painel - aquelas que obtiveram pontuação igual ou superior ao terceiro quartil, correspondendo às $25 \%$ mais cotadas.

\footnotetext{
8 "Não concordo. São coisas diferentes. Aprender a aprender possui um significado social e político na acepção original de Faure et al., 1972, na publicação intitulada Aprender a Ser, que está para além do ponto 38".
} 


\section{$\sim$

ISSN: 1984-6444 | http://dx.doi.org/10.5902/1984644434349

Quadro 1: Competências-chave do educador de adultos mais pontuadas no painel delphi.

\begin{tabular}{lcc}
\hline \multicolumn{1}{c}{ Itens } & Pontuação \\
\hline $\begin{array}{l}\text { 1. } \quad \text { Manifestar uma conduta ética: respeitar o sigilo e agir de acordo com a } \\
\text { ética profissional. }\end{array}$ & 89 \\
\hline 2. Ser capaz de compreender e valorizar a experiência do adulto. & 87 \\
\hline 3. Ser capaz de assumir o papel de facilitador da aprendizagem. & 85 \\
\hline $4 . \quad$ Ter domínio dos métodos e das técnicas de educação, formação e & 84.5 \\
aprendizagem de adultos. & \\
\hline 5. Ser capaz de gerir projetos de educação de adultos que incentivem a & 83 \\
aprender ao longo da vida, o que pressupõe sempre muita criatividade e & \\
empreendedorismo por parte do educador e a sua abertura ao desenvolvimento & \\
de um processo de reflexão-ação em permanência. & 83 \\
\hline 6. Ser capaz de proceder a processos de reconhecimento de adquiridos \\
experienciais, usando-os como ponto de partida para a construção de situações \\
formativas.
\end{tabular}

7. Ser capaz de iniciar o processo de aprendizagem com a criação de 82 condições emocionais propícias e utilizar aquilo que o participante já sabe ou faz, ou seja, utilizar o concreto-real como ponto de partida, de modo a que o ato formativo seja mais bem conseguido.

8. Ter domínio de métodos e técnicas de conceção, planificação, gestão, 82 organização, desenvolvimento, acompanhamento, controlo e avaliação dos processos de educação, formação e aprendizagem dos adultos.

9. Ser capaz de dar feedback adequado, relativo aos progressos do grupo e 81 à evolução de cada participante.

10. Ser capaz de construir um projeto em torno de intencionalidades 80.5 educativas, emergentes dos interesses e necessidades dos adultos, com metodologias apropriadas (ativas, participativas e construtivistas ou outras mais tradicionais) e conteúdos contextualizados e contextualizadores.

11. Ser assertivo (exemplo: ser capaz de dizer não, sem agredir). 80.5

\begin{tabular}{lc}
\hline 12. Aprender a aprender. & 80.5 \\
\hline 13. Ser capaz de induzir tarefas e dinâmicas potenciadoras da autorreflexão. & 80 \\
\hline $\begin{array}{l}\text { 14. Ser capaz de desenvolver um currículo e uma metodologia de trabalho "à } \\
\text { medida", ajustando os conteúdos e os percursos em função de cada pessoa }\end{array}$ & 80 \\
adulta, tendo em conta os seus contextos de vida pessoal, social e profissional. &
\end{tabular}

Fonte: Autores. 


\section{ตปthaคล์}

ISSN: 1984-6444 | http://dx.doi.org/10.5902/1984644434349

A análise do conteúdo das 14 "competências" de topo explicitadas no quadro 1 levou à emergência de uma matriz de categorias organizadas em 7 clusters: 1) competência ética; 2) competência de mobilização e valorização da experiência; 3) competência de facilitação da aprendizagem; 4) competência ao nível de métodos de educação, formação e aprendizagem; 5) competência de conceção, planeamento, gestão e avaliação do processo formativo; 6) competência de autodesenvolvimento; e 7) competência de ligação/articulação com a comunidade. A análise das restantes competências, que por limitações de espaço não é possível incluir no corpo do texto (ver apêndice), permitiu situar todos os itens nos 7 clusters que acabamos de mencionar.

\section{Discussão dos resultados}

Antes de ilustrarmos e interpretarmos os 7 clusters de competências subjacentes ao papel do educador de adultos, convém esclarecer que, embora o conceito de competência seja enquadrado por diferentes abordagens teóricas assentes em distintas epistemologias (PIRES, 2007), e apesar dos principais atores envolvidos no relançamento da EA em Portugal no final do século XX o terem feito a partir de um posicionamento humanista (MELO; MATOS; SILVA, 2006), não existiu qualquer indução junto dos membros do painel quanto ao significado do conceito, antes pelo contrário, ao assumir-se que todos eram especialistas em EA, deixou-se que as suas propostas refletissem livremente o teor do seu pensamento. Porém, tendo em conta a análise que se vai seguir, parece-nos apropriada a definição apresentada por Cavaco (2007, p.23) que nos diz ser a competência "referente à capacidade de mobilizar, num determinado contexto, um conjunto de saberes, situados ao nível do saber, saber-fazer e saber-ser, na resolução de problemas". Esclarece ainda a mesma autora que ela "não existe per se, está ligada a uma acção concreta e associada a um contexto específico". 


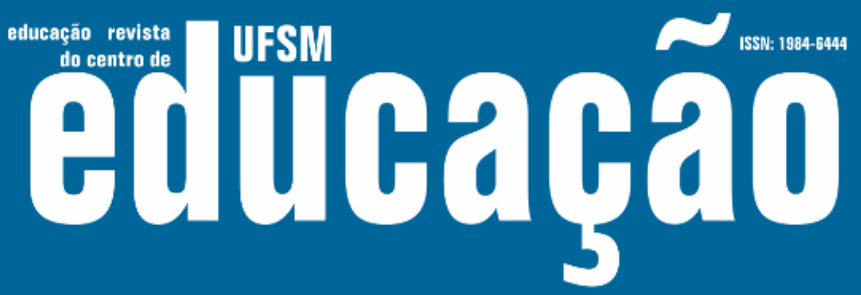

ISSN: 1984-6444 | http://dx.doi.org/10.5902/1984644434349

Competência ética. Esta é a competência mais pontuada pelos membros do painel, o que é revelador da enorme importância que assume no exercício do papel de educador. "Respeitar o sigilo e agir de acordo com a ética profissional" foi declaradamente expresso, o que nos remete para a importância da conduta ética estar presente, em permanência, em todos os atos educativos. Tal assume um significado acrescido quando o educador de adultos atua em situações de intimidade e privacidade, junto de pessoas e grupos vulneráveis (com trajetórias de vida difíceis, por vezes dramáticas, com frágil autoconfiança), pelo que the é requerido um zelo particular de "sabedoria prudencial" (BAPTISTA, 2014, p. 7) no exercício da atividade educativa e formativa, porque a ética do respeito, da integridade e da proteção da pessoa deve prevalecer em tudo o que fazemos, e perante a inexistência de um código de ética próprio, dados os frágeis processos de profissionalização do educador de adultos em Portugal e mesmo na esfera internacional, compreende-se que os membros do painel tenham colocado esta competência no topo da escala de importância.

Competência de mobilização e valorização da experiência do adulto. A segunda competência mais pontuada pelo painel. Na sua expressão: "compreender e valorizar a experiência do adulto"; "envolver o adulto em acções de revisitação, numa perspectiva de valorização e mobilização dos saberes cognitivos, afectivos e emocionais"; [levá-los] a reconhecer...as suas aprendizagens implícitas e possível transversalidade". Trata-se de uma competência especialmente requerida no âmbito de um balanço de competências de âmbito formal, na ocupação profissional de Técnico de Reconhecimento e Validação de Competências, ou na do agora designado Técnico de Orientação, Reconhecimento e Validação de Competências, no âmbito dos Centros Qualifica, cuja pontuação revela o quanto os membros do painel the reconhecem valor. Research voor Beleid (2010) incluem esta competência no cluster da análise de necessidades - uma categoria de competência que também aparece no perfil do Reino Unido (WAHLGRE, 2016) e na investigação do CEDEFOP - Centro Europeu para o Desenvolvimento da Formação Profissional (2013). Porém, a forma como esta competência aparece explicitada aponta para que os membros do painel não a associem a mero tecnicismo de aplicação de instrumentos. O que entrevemos 


\section{Authabูão}

ISSN: 1984-6444 | http://dx.doi.org/10.5902/1984644434349

é a valorização por parte do educador do que os adultos são como sujeitos únicos, das suas histórias de vida, a importância de entrar em relação criando oportunidades de os ajudar a tomar consciência do que constitui ou pode constituir valor e não do que pode fragilizar.

Competência de facilitação da aprendizagem. Esta é, de longe, a competência mais discriminada, associando-a os membros do painel a diferentes facetas: relacionais (criar ambientes dinâmicos e empáticos; inspirar confiança, motivar e encorajar; ser assertivo; dar feedback adequado); de personalização do processo formativo (currículo à medida, linguagem ajustada aos adultos em causa, prestar ajuda específica a cada educando); de promoção do desenvo/vimento pessoal; da reflexão (organizar debates de ideias, reflexão em grupo, estimular a pesquisa e a reformulação, estudar e investigar para melhor fundamentar as opiniões); de abertura à diversidade cultural (compreender culturas e valores diversos); de liderança de grupos (de forma sutil); de construtor de sentido (situações educativas significativas); de mobilização de conhecimentos da própria história de vida; de manipulação de ferramentas informáticas. Trata-se de um papel de grande complexidade que, em geral, demarca o afastamento de transmissor de informação ou de "educação bancária", segundo Freire, e que pode ser informado por vários posicionamentos teóricos (OLIVEIRA, 2004).

A análise das ideias geradas mostra que dos 53 itens, 26 se referem à explicitação desse papel e entrevê-se que os intervenientes no painel adotam referenciais de leitura que combinam, de forma dominante, os enquadramentos humanista e crítico: "utilizar uma linguagem corporal potenciadora de um clima de confiança, aceitação e acolhimento", "demonstrar disponibilidade para ouvir - um ouvir atento"; "ser capaz de praticar uma cultura de intimidade, familiaridade e proximidade adulta e crítica com a comunidade e com os participantes, sem que a exigência e o rigor desvaneçam". Os aspetos afetivos e emocionais inerentes à relação aparecem com grande destaque, sendo preciso saber lidar de forma profissional com esta dimensão dos processos educativos, de forma a estruturar as relações na base da salvaguarda da dignidade e equidade e não em assimetrias que em nada contribuem para o respeito mútuo. As antinomias (os controlados e descontrolados, os seguros e 


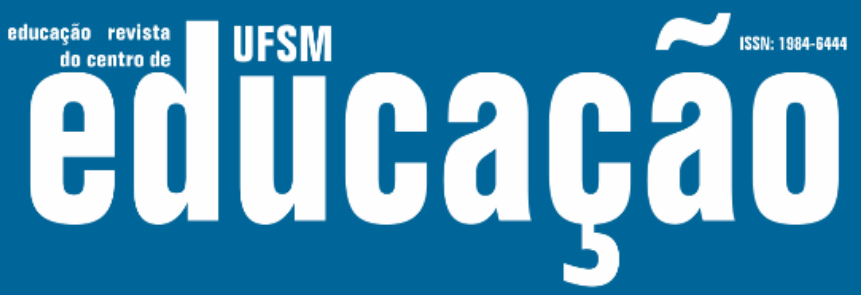

ISSN: 1984-6444 | http://dx.doi.org/10.5902/1984644434349

inseguros, os frágeis e os fortes, os dominadores e dominados etc.) são de arredar e os processos emocionais devem ser remetidos e situados na nossa humanidade comum: "não culminar em abraços de lamúrias, ou construir pilares de lamentações; "não chorar com os adultos" é fundamental para toda a "produção de obras".

Competência ao nível de métodos de educação, formação e aprendizagem. Esta é uma competência clássica e basilar na EA, estando relacionada com o domínio que o educador precisa de ter, dadas as múltiplas áreas e contextos de trabalho, sobre uma diversidade de métodos formativos que permitem desenvolver trabalho focado no educando, no grupo ou na comunidade (KHALER et al., 1985). É uma competência situada predominantemente na esfera técnica/pedagógica/didática de acordo com os perfis de estudos anteriores (BECHTEL, 2008, apud WAHLGRE, 2016). Entre os itens propostos pelos membros do painel encontramos: "metodologias apropriadas (ativas, participativas e construtivistas ou outras mais tradicionais) e conteúdos contextualizados e contextualizadores". Neste âmbito, destacamos o termo "apropriadas", o qual remete para uma escolha criteriosa, tendo em conta as especificidades do trabalho educativo com adultos e dos contextos em que nos situamos. Destacamos também "conteúdos contextualizados e contextualizadores", "ajustando os conteúdos (...), tendo em conta os (...) contextos de vida pessoal, social e profissional", ou ainda integrar a "aprendizagem conteúdal" nos contextos de vida, de trabalho, ambiental e social, da ética relacional. Estas propostas reiteram o cariz identitário da EA arredado da estrutura disciplinar e fragmentadora do conhecimento (JARVIS, 2004) - a boa prática não parte dos conteúdos para a pessoa, mas da elevação da pessoa com 0 mundo (ROMÃO, 2001) a novos horizontes de perspetiva, competência e ação no mundo, valorizando-se a "ideia de totalidade e de inter-relação complexa do real" (BARROS, 2013, p. 47).

Competência de conceção, planeamento, gestão e avaliação do processo formativo. Igualmente remetendo-nos para competências fundamentais do educador de adultos, podemos dizer que, na verdade, estão aqui implicadas várias competências. Por exemplo, considerando os diversos perfis de competência-chave europeus, embora diversamente designados, encontramos competências 


\section{Tilusm Eulloabato}

ISSN: 1984-6444 | http://dx.doi.org/10.5902/1984644434349

metodológicas, competências de planeamento e gestão, de avaliação, desenho da formação e avaliação das aprendizagens. No Reino Unido o planeamento, a gestão e a avaliação surgem como competências separadas (WAHLGRE, 2016). Este cluster, apesar de se situar no domínio das competências técnicas, é essencial para o desempenho dos diversos papéis do educador de adultos (LOUREIRO, 2009; RESERCH VOOR BELIED, 2010), sendo de elevada complexidade e sofisticação. Posicionando-se, sobretudo, na esfera transversal, ele permite assegurar a qualidade dos processos educativos/formativos. A este respeito, os elementos do painel enfatizaram os seguintes aspetos: "usar como ponto de partida o concreto-real'; "temas significativos, de modo a serem o ponto de partida para o processo de educação-formação"; "competências desenhadas sem formulações ambíguas e vagas"; "gerir o tempo"; "competente na avaliação por uso de competências".

Competência de autodesenvolvimento. Esta competência é igualmente complexa e supõe um processo contínuo de desenvolvimento. Implica "reflexão-ação em permanência", "ser capaz de pensamento crítico". Como tal, e como propuseram os membros do painel, está fortemente articulada com o "aprender a aprender", que é conceitualizado como "um processo complexo - ou uma constelação de processos coextensivo à duração da vida, pelo qual se adquirem e modificam as capacidades para a aquisição de conhecimento, a solução de problemas e a captação do significado da experiência" (SMITH, 1996, p. 418). Segundo Oliveira (1998), aprender a aprender pressupõe três dimensões de desenvolvimento: aprender sobre a aprendizagem, que implica que o sujeito desenvolva uma conceção mais elaborada do que é aprender, perspetivando a aprendizagem de forma mais holística (incluindo, para além de processos lógicos, racionais e lineares, os processos intuitivos, metafóricos e tácitos); aprender como aprender, intrinsecamente ligada a "um processo contínuo de aquisição e desenvolvimento de mais e melhores capacidades de aprendizagem" (OLIVEIRA, 1998, p. 573), reconhecendo-se que é um processo complexo, em virtude das aprendizagens humanas serem de ordem muito diversa (espontâneas, auto-planeadas, prescritas, relacionais, técnicas, de autodesenvolvimento etc.) e de implicarem diferentes níveis de complexidade, estando ainda fortemente dependentes do contexto, seja ele político, conteúdal, 


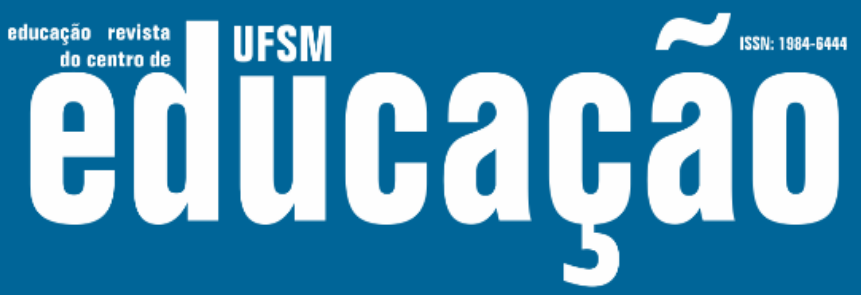

ISSN: 1984-6444 | http://dx.doi.org/10.5902/1984644434349

pessoal, cultural ou comunitário; aprender sobre si como educando, pressupõe um processo em que o sujeito vai compreendendo os seus sistemas de significação (deles tomando consciência e de onde vêm) e reorganizando as suas estruturas de significado num processo concomitante ao desenvolvimento da reflexividade crítica e de crescente emancipação (MEZIROW, 1998). A importância do educador de adultos participar no desenvolvimento desta dimensão reflexiva foi claramente ilustrada pelos membros do painel: "abertura ao próprio desenvolvimento e autorreflexão"; "modificar as perspetivas de significado próprias"; "capaz de refletir sobre a própria vida para crescimento e desenvolvimento pessoal'. Neste mesmo sentido aponta o CNE (2013), ao afirmar que a formação deve, para além da informação, investir fortemente no "aprender a aprender" preparando as pessoas para intervir em todas as dimensões da vida em sociedade: a família, o trabalho, a comunidade, o lazer.

Competência de ligação/articulação com a comunidade. Para a questão de fundo levantada por Kurantowicz e Lucio-Villegas (GUIMARÃES, 2016, p.199) "pode a educação e a aprendizagem dos adultos ser compreendida se não se considerar a comunidade e as vidas quotidianas das pessoas?" - as respostas dos membros do painel vão, como seria de esperar, em sentido oposto: é necessário "praticar uma cultura de intimidade, familiaridade e proximidade adulta e crítica com a comunidade"; é importante "gerir o contexto integrando o contexto de vida, o contexto de trabalho, o contexto ambiental e social, o contexto da ética relacional e da aprendizagem conteúdal" no processo formativo e "estabelecer ligações de coresponsabilização". Desenvolver a competência de articulação do trabalho educativo com os contextos de vida e a comunidade é, portanto, um requisito da qualidade do trabalho do educador de adultos. Não sendo fácil, porque a comunidade é um espaço diverso e suscetível ao conflito (FRAGOSO; LUCIO-VILLEGAS, 2014), há três pilares que estes últimos autores, partindo da matriz de pensamento Freiriana, consideram fundamentais: o coletivo, o diálogo e a transformação. Contrariando o individualismo dominante, a opção pelo coletivo é vista por eles como "uma aposta pela diversidade, pela descoberta do que nos une e simultaneamente pela descoberta do que nos diferencia" (FRAGOSO; LUCIO-VILLEGAS, 2014, p. 60). O diálogo reconhece o outro "e supõe a existência de um conhecimento anterior que se põe em jogo quando se 


\section{Autนaดูลิ}

ISSN: 1984-6444 | http://dx.doi.org/10.5902/1984644434349

produzem situações educativas" (FRAGOSO; LUCIO-VILLEGAS, 2014, p. 60). Neste mesmo sentido, como referem Soares e Pedroso (2013, p. 256), "ser educador [de adultos] exige uma postura aberta e dialógica, de comunhão em relação ao contexto".

\section{Considerações finais}

O conjunto de competências que interpretamos dá-nos uma ideia bem sustentada da centralidade que ocupam ou devem ocupar na formação dos educadores de adultos no plano nacional e internacional. Nelas está profundamente presente a ideia de transversalidade (ao nível da ética, das competências relacionais, comunicacionais etc.) que permite ao educador de adultos atuar em vários domínios (salvaguardadas as respetivas especificidades). A compreensão das pessoas em contextos é igualmente uma tônica subjacente às competências propostas, destacando-se o termo ligação, porém, não basta partir desta premissa com apropriação intelectual, é necessário, fenomenologicamente, realizar a interdependência de tudo e todos. É também manifesto que se trata de competências de elevada complexidade, das quais formações breves só quimericamente dariam conta - uma posição consistente, comprometida com mudanças desejáveis na sociedade, requer opções claras, tempo e fundações firmes. A este respeito, os membros do painel, demarcando-se da miopia da racionalidade técnica, apontam para uma sustentação teórica dos saberes e competências do educador de adultos nos quadros humanista, reflexivo e crítico. Uma formação sólida e comprometida com o bem-estar não só individual, mas também coletivo é imperiosa; o compromisso com ideias e valores benéficos para todos, não apenas a curto, mas igualmente a longo prazo, é crucial para possibilitar a inversão das tendências erosivas dominantes. 


\section{D usm Futbabुa}

ISSN: 1984-6444 | http://dx.doi.org/10.5902/1984644434349

\section{Referências}

AMADO, João. Manual de investigação qualitativa em educação. 3. ed. Coimbra: Imprensa da Universidade de Coimbra, 2017.

BARROS, Rosanna. O Movimento das Histórias de Vida e a Educação de Adultos de Matriz Crítica: ideias e conceitos em contexto. Revista Lusófona de Educação, [S.I.], v. 23, n. 23, julho 2013.

BARROS, Rosanna. Diversificação, Massificação e Esvaziamento da Oferta de Educação e Formação de Adultos (EFA) em Portugal: Algumas Reflexões e Inquietações. Revista Portuguesa de Pedagogia, [S.I.], p. 13-36, dez. 2016.

BAPTISTA, Isabel (Org.). Instrumento de regulação ético-deontológica: Carta ética. 2014. Disponível em: http://www.spce.org.pt/PDF/CARTAETICA.pdf. Acesso em: 13 jun. 2018.

BRANDÃO, Carlos Rodrigues. Vocação de criar: anotações sobre a cultura e as culturas populares. Cadernos de Pesquisa, São Paulo, v. 39, n. 138, p.715-746, set./dez. 2009.

CAVACO, Cármen. Reconhecimento, validação e certificação de competências: complexidade e novas atividades profissionais. Revista de Ciências da Educação, São Paulo, v. 1, n. 2, p.21-34, 2007.

CEDEFOP (European Centre for the Development of Vocational Training). Trainers in continuing VET: Emerging competence profile. Luxembourg: Publications Office of the European Union, 2013.

DAVE, Ravindra. (Org.). Fundamentos de la educación permanente. Madrid: Santilla, 1979.

FRAGOSO, António; LUCIO-VILLEGAS, Emílio. A mediação na comunidade e no desenvolvimento comunitário: tendências e potencialidades. Revista Lusófona de Educação, [S.I.], v. 28, n. 28, mar. 2015.

FRAGOSO, António; KURANTOWICZ, Ewa; LUCIO-VILLEGAS, Emilio. Between global and local: adult learning and development. Frankfurt: Peter Lang, 2011.

GUIMARÃES, Paula. Ocupações da educação de adultos e desafios à profissionalização: Tarefas e atividades desenvolvidas em contexto de trabalho. Revista de Estudos Curriculares, [S.I.], v. 2, n. 7, p.57-82, 2016. 


\section{U usm \\ $\sim$

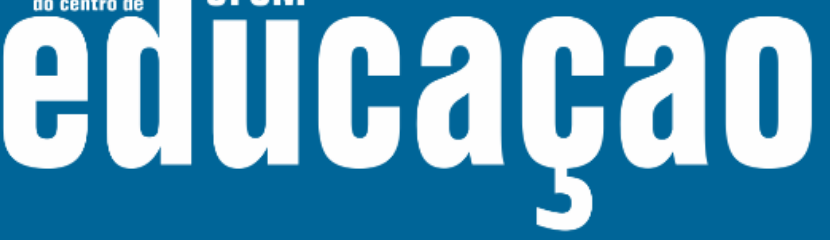

ISSN: 1984-6444 | http://dx.doi.org/10.5902/1984644434349

GONÇALVES, Maria José. Researching and Transforming Adult Learning and Communities: The Local/Global Context. Revista Lusófona de Educação, [S.I.], v. 35, n. 35, june 2017.

IRELAND, Timothy Denis; SPEZIA, Carlos Humberto (Orgs.). Educação de adultos em retrospectiva: 60 anos de CONFINTEA. Brasília: Unesco, 2012.

JARVIS, Peter. Adult education \& Lifelong learning: Theory and practice. 3. ed. Nova York: Routledge, 2004.

Kahler, Alan et al. Methods in adult education. Danville: The Interstate Printers \& Publishers, 1985.

LIMA, Licínio Carlos. Revisitação gelpiana da educação permanente: Ambiguidades e erosão política de um conceito. Investigar em Educação, [s.I.], v. 2, n. 5, p.53-73, 2016.

LOUREIRO, Armando. 0 trabalho técnico-intelectual em educação de adultos: Contribuição etnossociológica para a compreensão de uma ocupação educativa. Cascais: Sururu, 2009.

MELO, Alberto. Que educação de adultos para uma sociedade em mutação? In Actas das Jornadas de Educação de Adultos em Portugal: Situação e Perspectivas. Coimbra: Fpce, 1996.

MELO, Alberto. Agir localmente, pensar globalmente: Testemunho de um percurso inspirado em Paulo Freire. Revista Portuguesa de Pedagogia, 35 (1), p.115-122, 2001.

MELO, Alberto; MATOS, Lisete; SILVA, Olívia Santos. S@ber +: Programa para o desenvolvimento e expansão da educação e formação de adultos, 19992006. Lisboa: Anefa/gmefa.

MEZIROW, Jack. On critical reflection. Adult Education Quarterly, [S.I.], v. 48, n. 3, p.185-198, 1998.

OLIVEIRA, Albertina Lima de. Aprender a aprender: Para uma construção contínua do saber e do sujeito que o elabora. In: GOMES, Joaquim Ferreira. Ensaios de homenagem a Joaquim Ferreira Gomes. Coimbra: Universidade de Coimbra, 1998. p. 567-579.

OLIVEIRA, Albertina Lima de. 0 professor enquanto facilitador da aprendizagem. Psychologica, Coimbra, p.523-534, 2004. 


\section{usm Eutlaghat}

ISSN: 1984-6444 | http://dx.doi.org/10.5902/1984644434349

PIRES, Ana Luisa de Oliveira. Reconhecimento e validação das aprendizagens experienciais: Uma problemática educativa. Sísifo: Revista de Ciências da Educação, n. 2, p. 5-20, 2007.

PORTUGAL. Conselho Nacional de Educação. Recomendação sobre políticas públicas de Educação e Formação de Adultos. Diário da República, 2. série, N.ํ 95 , 17 de maio de 2013.

QUINTAS, Helena Luísa Martins. Educação de adultos: vida no currículo e currículo na vida. Lisboa: Perspectivas e Reflexões, 2008.

RESEARCH VOOR BELEID. Key competencies of learning professionals: Contribution to the development of a reference framework of key competencies for adult learning professionals. Zoetemmer: Research voor Beleid. 2010.

ROMÃO, José Eustáquio. O círculo de cultura. Revista Portuguesa de Pedagogia, v.35, n.1. p. 123-147, 2001.

ROTHES, Luis. A formação dos educadores de adultos em Portugal: Trajectos e tendências. Forum, v.34, p. 35-62, 2003.

SEIXAS, Ana Maria et al. Editorial. Revista Portuguesa de Pedagogia, [S.I.], v. 1, n. 50, p.5-12, dez. 2016.

SIMÕES, António. Educação permanente e formação de professores. Coimbra: Livraria Almedina, 1979.

SMITH, Robert. Learning to learn. In: TUIJNMAN, Albert C. International encyclopedia of adult education and training.[S.I.]: Elsevier Science, 1996. p. 418427.

SOARES, Leôncio José Gomes. As especificidades na formação do educador de jovens e adultos: Um estudo sobre propostas de EJA. Educação em Revista, v.27, n.2, p. 303-322, 2011.

SOARES, Leôncio José Gomes; PEDROSO, Ana Paula Ferreira Pedroso. Dialogicidade e a formação de educadores na EJA: As contribuições de Paulo Freire. Educação Temática Digital, v.15, n.2, p.250-263, 2013.

SURIKOVA, Svetlana et al. Competencies of adult education facilitators: transnational comparison (India, Lithuania and Latvia). In: NUISSL, e et al. Facets of professionalization among adult education teachers: Eurasian perspectives. New Delhi: Sarup Book Publishers, 2015. p. 49-65. 


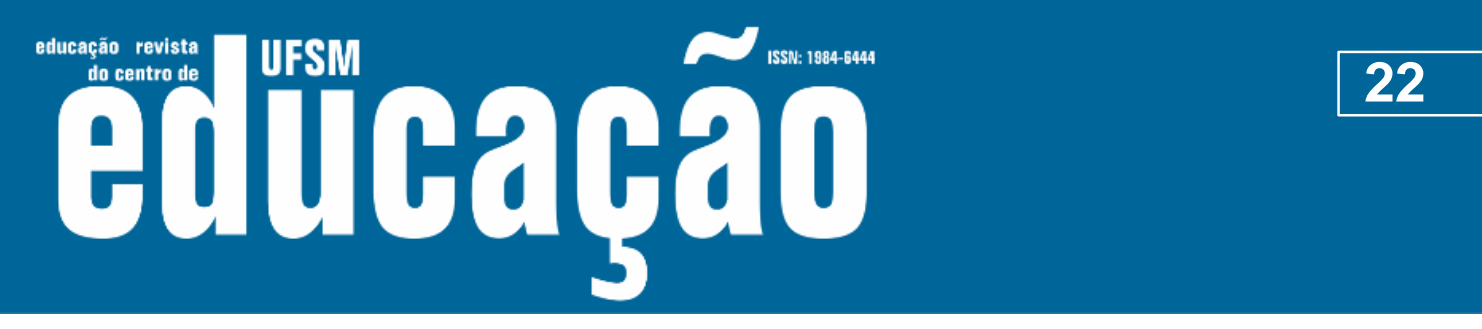

ISSN: 1984-6444 | http://dx.doi.org/10.5902/1984644434349

WAHLGRE, Bjarne. Adult educators' core competences. International Review of Education,v. 62, n.3, p. 343-353, 2016.

\section{Apêndice}

Competências-chave do educador de adultos até ao $3^{\circ}$ quartil

15. Ser capaz de inspirar confiança, motivar e encorajar

79.50

16. Ser capaz de corresponsabilizar e mobilizar o adulto para novos cenários de 79.50 aprendizagem, encorajando-o(s) a aprender mais

17. Ser capaz de estimular e organizar o debate de ideias entre todos os 79 participantes, dentro de um espírito de escuta mútua e da procura coletiva de um grau superior de compreensão.

18. Ser capaz de atuar de forma flexível e imparcial quanto às diferenças intrínsecas dos adultos

19. Ter elevada capacidade de observação da linguagem não-verbal: a importância dos silêncios, "leitura" de sinais corporais, de expressões faciais, etc.

20. Saber criar ambientes de educação-formação dinâmicos e empáticos

21. Ser capaz de comunicar bem, em termos verbais e não-verbais (produzir discursos orais e escritos com versatilidade, usar linguagem oral e escrita ajustada aos adultos em causa, utilizar uma linguagem corporal potenciadora de um clima de confiança, aceitação e acolhimento).

22. Ser capaz de mobilizar, assegurar e orientar momentos de debate e reflexão em grupo

23. Demonstrar disponibilidade para ouvir - um ouvir atento (preocupações em reformular).

24. Ser capaz de compreender culturas e valores diversos e de interagir com os mesmos.

25. Ser capaz de descobrir, em cada aprendente, as suas forças e fraquezas quando tenta aprender algo, de modo a poder prestar-Ihe a ajuda específica de que necessita 26. Ser capaz de articular com os processos de educação-formação iniciativas de natureza social, cultural, cívica ou ambiental, de expressão artística, de lazer ou desporto, de desenvolvimento socioeconómico, de empreendedorismo, etc., em que as pessoas adultas se sintam fortemente empenhadas

27. Ser capaz de desenvolver nos aprendentes adultos uma maior capacidade de análise crítica, testando-a, em primeiro lugar, no próprio processo formativo, mas sempre numa perspetiva pedagógica, que conduza a propostas construtivas de melhoria e não apenas a reações negativas e autodestrutivas.

28. Ser competente na utilização de práticas que (des)dramatizam os erros dos participantes e partir deles para criar oportunidades de aprendizagem ou para encorajar o aprendente a procurar soluções

29. Ser capaz de desempenhar o papel de facilitador, gerador de momentos de partilha e descoberta das potencialidades dos adultos, levando-os a reconhecer, nas suas próprias produções de experiências, as suas aprendizagens implícitas e possível transversalidade

30.Ser capaz de modificar as perspetivas de significado próprias (abertura ao próprio desenvolvimento e autorreflexão).

31. Demonstrar flexibilidade de ajustamento a adultos diferenciados, levando-os a sentir que temos a preocupação de personalizar os nossos papéis. 


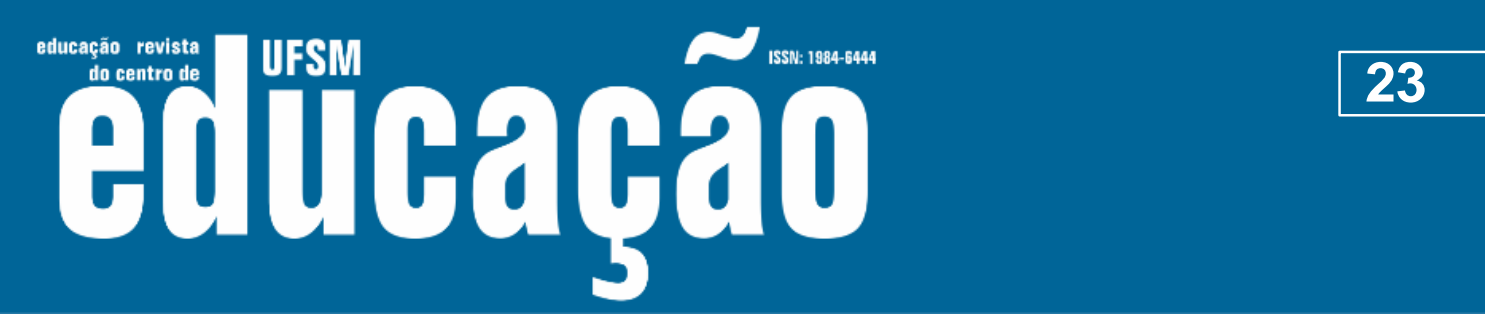

ISSN: 1984-6444 | http://dx.doi.org/10.5902/1984644434349

32. Ser capaz de construir "situações geradoras", contextos em que as pessoas adultas possam "crescer" e sentir-se interdependentes e solidárias e onde as aprendizagens surjam praticamente, por vezes impercetivelmente, como "efeitos colaterais" positivos.

33. Ser capaz de gerir um grupo, trabalhando com ferramentas de gestão de pessoas

34. Ser capaz de se mostrar inovador quanto às suas práticas 73.00 35. Ser capaz de obter toda a informação possível sobre os temas que mais afetam a processo de educação-formação

36. Ser capaz de funcionar como um "construtor de sentido", contribuindo para que os educandos possam viver como pertinentes as situações educativas em que se encontram inseridos.

37. Ser capaz de lidar adequadamente com os aspetos afetivos e emocionais inerentes à relação (saber ter um distanciamento emocional suficiente para não se ver enredado nos problemas e dificuldades da vida dos adultos: por exemplo, não culminar em abraços de lamúrias, ou construir pilares de lamentações; "não chorar com os adultos" é fundamental para toda a "produção de obras" com os mesmos).

38. Ser capaz de refletir sobre a própria vida e sobre a riqueza desta no seu crescimento e desenvolvimento pessoal.

39.Ser capaz de operar com os conhecimentos trazidos da sua própria história de vida.

40. Ser capaz de estimular o adulto a pesquisar e a fazer as reformulações necessárias para obter um produto de qualidade

41.Ser capaz de praticar uma cultura de intimidade, familiaridade e proximidade adulta e crítica com a comunidade e com os participantes, sem que a exigência e o rigor desvaneçam.

42. Ser capaz de levar o aprendente a avançar na compreensão pessoal das situações-problema em análise, procurando atingir um equilíbrio constante entre a experiência concreta e a análise distanciada.

43. Ser capaz de pensamento crítico e avaliação dos percursos de educação, formação e aprendizagem realizados pelos adultos.

44. Ser capaz de gerir o contexto de aprendizagem dos adultos-educandos, integrador de múltiplas vertentes: o contexto de vida, o contexto de trabalho, o contexto ambiental e social, o contexto da ética relacional e da aprendizagem conteúdal.

45. Tolerância da ambiguidade e da incerteza

46. Saber ser lider, sem liderar

47. Ser capaz de levar o adulto a consciencializar que a opinião subjectiva não chega 67.00 e que é preciso estudar e investigar para melhor fundamentar (ou acabar por alterar) as opiniões anteriormente emitidas.

48. Ser capaz de demonstrar capacidade para estabelecer ligações de coresponsabilização e envolver o adulto em acções de revisitação, numa perspectiva de valorização e mobilização dos saberes cognitivos, afectivos e emocionais. 49. Ser competente na avaliação por uso de competências, devendo estas ser desenhadas sem formulações ambíguas e vagas, pois tal tem dificultado uma avaliação objectiva ou uma orientação precisa do processo educativo.

\begin{tabular}{lc}
\hline 50. Ser capaz de promover o empreendedorismo no adulto e a pro-actividade & 66.00 \\
\hline 51. Ser capaz de gerir o tempo & 63.00 \\
\hline 52. Manipular ferramentas informáticas & 60.00 \\
\hline 53. Ser capaz de agir como um encenador que assume a responsabilidade em & 52.00 \\
supervisionar e dirigir directamente pessoas, com histórias de vida mais ou menos & \\
dramáticas, decidindo e assegurando, de uma forma partilhada, a pertinência e & \\
qualidade dos elementos explorados em contextos de vida diversificados, com vista a & \\
\hline
\end{tabular}




\section{Tusm 2

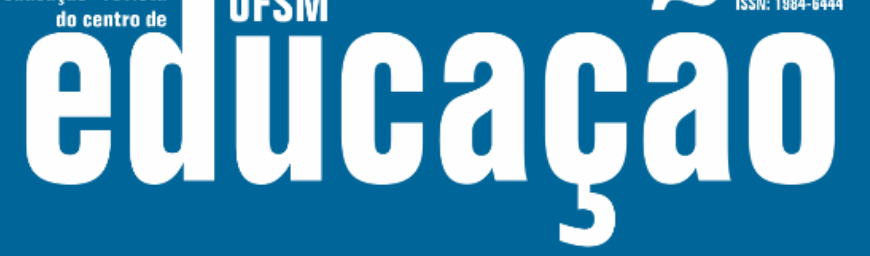

ISSN: 1984-6444 | http://dx.doi.org/10.5902/1984644434349

\section{Correspondência}

Marco Antônio Franco Amaral - Professor no Instituto Federal Goiano - Morrinhos, Goiás, Brasil.

Albertina Lima Oliveira - Professora Auxiliar da Faculdade de Psicologia e de Ciências da Educação da Universidade de Coimbra, Portugal.

Instituto Federal Goiano - Campus Morrinhos. BR-153, km 633 - CEP: 75.650000, Zona Rural, Morrinhos, Goiás, Brasil

E-mail: marco.amaral@ifgoiano.edu.br - aolima@fpce.uc.pt

iD ORCID: https://orcid.org/0000-0002-3573-3795 - https://orcid.org/0000-0001-9521$528 \mathrm{X}$

\section{(9) $(1) \Theta$}

This work is licensed under a Creative Commons Attribution-NonCommercial 4.0 International (CC BY-NC 4.0) 